\title{
Threshold Effects in the Foreign Aid-Economic Growth Relationship: The Role of Institutional Quality and Macroeconomic Policy Environment
}

\author{
Daniel Komlan Fiodendji ${ }^{*}$, Kodjo Evlo ${ }^{2}$ \\ ${ }^{1}$ Departement of Economics, University of Ottawa, Ottawa, Canada \\ ${ }^{2}$ Faculté des Sciences Economiques et de Gestion (FASEG), Université de Lomé, Lomé, Togo \\ Email: *dansegun@yahoo.com, kodjo_evlo@yahoo.com
}

Received August 31, 2013; revised September 30, 2013; accepted October 10, 2013

Copyright (C) 2013 Daniel Komlan Fiodendji, Kodjo Evlo. This is an open access article distributed under the Creative Commons Attribution License, which permits unrestricted use, distribution, and reproduction in any medium, provided the original work is properly cited.

\begin{abstract}
Since the influential paper of [1], the issue relating to the conditions in recipient countries has become central in the foreign aid debate. Scholars and policymakers alike are interested in identifying the conditions which make foreign aid more effective. To contribute to this growing debate, this paper investigates the role of macroeconomic policy environment, institutional policy and a combination of these two previous variables in aid-growth relationship. The empirical analysis is based on a panel data set including 13 ECOWAS $^{1}$ countries during the period from 1984 to 2010. Using a modified panel threshold model, the evidence strongly supports the view that the relationship between aid and economic growth is nonlinear with a unique threshold. The paper finds that a stable macroeconomic environment and better institutional quality are sine qua non for the effective contribution of aid to sustainable growth in ECOWAS countries. Furthermore, we find that institutional quality is an important determinant condition which allows aid affects economic growth. One of main contributions of this paper is to successfully identify the conditions under which the aid has a positive impact on economic growth. It is desirable to keep the combination condition in States II and IV (the macroeconomic policy environment is below or above and institutional quality above their threshold respectively) because it may be helpful for the achievement of sustainable economic growth. The results seem to indicate that bad institutional quality may have detrimental effects on economic growth. This will be an important result for the policymakers and international financial institutions, which increasingly favour conditionality and selectivity in the allocation of aid resources. The major policy implication of our results is not a call for a reduction of foreign aid but rather a call for rethinking strategies for international assistance and redesigning existing aid programs.
\end{abstract}

Keywords: Foreign Aid; Economic Growth; Threshold Effects; Institutional Quality; Economic Policy

\section{Introduction}

The impact of foreign aid on economic growth in developing countries has been emphasized in the literature over the past few decades. The importance of this topic stems from its policy-relevance, given the focus African countries and their financial and technical partners put on poverty reduction in the conduct of development policy. Several studies have tried to capture the effectiveness of

\footnotetext{
"Corresponding author.

${ }^{1}$ Economic Community of West African States (Benin, Burkina Faso, Côte d'Ivoire, Gambia, Ghana, Guinea, Guinea Bissau, Mali, Niger, Nigeria, Senegal, Sierra Leone and Togo). 13 ECOWAS countries were selected in a panel regression due to data availability.
}

aid on economic growth and poverty reduction. Previous empirical studies on foreign aid and economic growth come to contradictory results. There are three possible results regarding the impact of foreign aid on growth: 1) foreign aid has no effect on economic growth; 2) foreign aid has a positive impact on growth, but with diminishing returns; and 3) foreign aid has a conditional relationship with economic growth, helping to accelerate growth only under certain circumstances.

The negative or, at best, insignificant growth effect of aid supported by the majority of studies lies in the central assumption that the relationship between aid and growth is uniform across countries. [2] did not find evidence on 
the relationship between aid and growth rate in developing countries. [3] finds that aid has no impact on growth or investment. However, $[4,5]$ report a positive effect of aid on economic growth, although aid is shown to have diminishing returns. The recent literature has tried to establish that aid works under certain conditions. Various scholars have argued that aid is indeed effective in good policy environments (see [6,7]).

Since the influential paper of [1], the issue relating to the conditions in recipient countries has become central in the foreign aid debate. Scholars and policymakers alike are interested in identifying the conditions which make foreign aid more effective. Does aid effectiveness vary with the recipient country or with domestic regime type? Is foreign aid more effective at promoting growth in good macroeconomic environments or in settings where institutional quality is good?

Motivated by these questions, the crucial goal of this paper is to contribute to the inconclusive debate on aid and growth relationship. More specifically, this study empirically examines the link among aid and growth conditioned to the role of macroeconomic policy environment and institutional quality in ECOWAS countries.

Developing countries are in fact specified by the various economic problems these countries are often faced. For example, a low level of income, a high level of unemployment, a very low industrial capacity utilization, and a high poverty level. In addressing these problems, foreign aid has been suggested as a veritable option for augmenting the insufficient domestic resources. While some countries that have benefited from foreign assistance at one time or the other have grown such that they have become aid donors (South Korea, China etc.), majority of countries in Africa have remained backward. ECOWAS countries have continued to benefit from all sorts of foreign assistance and in fact still collect at least as much as the amount collected in the early 1980 s, yet socio-economic development has remained dismal. Whilst there could be so many determinants explaining these unfavourable trends, the incessant socio-political crisis, policy inconsistencies, macroeconomic instability and bad institutional quality evident in many ECOWAS countries which are indeed indicators of poor policy framework, should give one a pause. On the contrary, however, [8] suggested that empirically, aid is effective everywhere, even in bad policy environments.

To address these issues, this paper applies an alternative modelling approach on which uses a threshold variable to investigate whether the relationship between aid and growth is different in each sample grouped on the basis of certain thresholds. Threshold models are simple yet efficient methods to capture nonlinearities in cross section and time series models. They split the sample into classes based on the value of observed variables according to threshold values. Indeed, there are various ways to identify the presence of a threshold in an economic relationship, depending on the criteria used to determine how to split the sample. [9] applies the technique of exogenously imposed data splits as a straightforward technique to select sub-sample. In order to determine the existence of threshold effects between two variables is different from the traditional approach in which the threshold level is determined exogenously. However, under this approach both the number of regimes and the location of sample splits are arbitrarily selected and not based on prior economic guidance. Another limitation of this approach is that it is not possible to derive confidence intervals for the location of the threshold. The robustness of the results from the conventional approach is likely to be sensitive to the level of the threshold. The econometric estimator generated on the basis of exogenous sample splitting may also generate serious inferential problems (for further details, see [10,11]). Threshold models have some popularity in current applied econometric practice. The model splits the sample into classes based on the value of an observed variable-whether or not it exceeds some threshold. When the threshold is unknown (as is typical in practice) it needs to be estimated, and this increases the complexity of the econometric problem. A theory of estimation and inference is fairly well developed for linear models with exogenous regressors, including [10-13].

These papers explicitly exclude the presence of endogenous variables, and this has been an obstacle to empirical application, including panel models. Advantages of the endogenous threshold regression technique over the traditional approach are that: 1) it does not require any specified functional form of non-linearity, and the number and location of thresholds are endogenously determined by the data; and 2) asymptotic theory applies, which can be used to construct appropriate confidence intervals. A bootstrap method to assess the statistical significance of the threshold effect, in order to test the null hypothesis of a linear formulation against a threshold alternative, is also available. This approach is supposed to eliminate multicollinearity problems among some of the regressors, in order to be able to identify the partial effects of these variables on the dependent variable. For this purpose we used a sample of 13 ECOWAS countries covering the period 1984-2010.

For the purpose of presentation, the rest of this paper is structured as follows: Sections 2 describes the evolution of aid in ECOWAS countries, Section 3 provides econometrics methodology, Section 4 sets out our empirical analysis and interpretation of our results, and Section 5 provides concluding remarks.

\section{Foreign Aid in ECOWAS Countries}

Figure 1 depicts the evolution of the ratio of total foreign aid to GDP. For the whole ECOWAS countries, the 


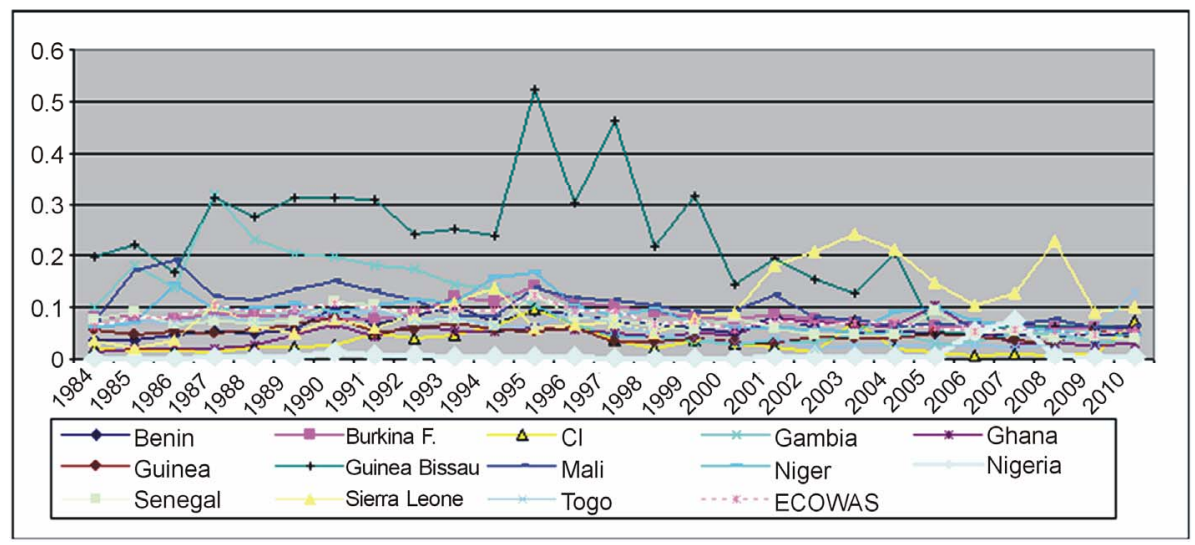

Figure 1. Trends in Aid to ECOWAS countries, 1984-2010.

average variations seem to stable around $10 \%$.

In Guinea Bissau, aid has reached its highest levels in the 1990 s, with a peak of $51 \%$ in 1996 . Three countries have received relatively small amounts of aid. These countries are Côte d'Ivoire, Guinea and Nigeria. Furthermore in the latter country, the ratio of aid was around $1 \%$ during 1990s. After that, it became almost nil from 1995 to 2005 before rising slightly and making a jump to $8 \%$ in 2007 . The trend is stable at our countries sample level. However, for Sierra Leone, there is a change sawtooth. For example, the ratio of aid is around 5\% in 1990 except for 2003 (22\%) and 2008 (21\%). In general case, we have been observed some convergence of ratio of aid for most of ECOWAS countries from the 2000s. In fact the ratio of aid is between $1 \%$ and $10 \%$.

\section{Econometric Methodology}

Threshold models are simple yet efficient methods to capture nonlinearities in cross section and time series models. The main purpose of this paper is to use a threshold variable to investigate whether the relationship between Aid and economic growth through the policy environment and institutional quality is different in each sample grouped on the basis of certain thresholds. The endogenous determination of threshold effects between variables is different from the traditional approach in which the threshold level is determined exogenously. If the threshold level is chosen arbitrarily, or is not determined within an empirical model, it is not possible to derive confidence intervals for the chosen threshold. The robustness of the results from the conventional approach is likely to be sensitive to the level of the threshold. The econometric estimator generated on the basis of exogenous sample splitting may also pose serious inferential problems (for further details, see $[10,11]$ ).

\subsection{Econometric Framework: Panel Threshold Models}

[10] developed the econometric techniques appropriate for threshold regression with panel data. Allowing for fixed individual effects, the panel threshold model divides the observations into two or more regimes, depending on whether each observation is above or below the threshold level. The general specification threshold model takes the following form:

$$
\begin{aligned}
y_{i t}= & \mu_{i}+\sum_{k=0}^{K-1} \beta_{k+1} x_{i t} I\left(\gamma_{k}<q_{i t} \leq \gamma_{k+1}\right) \\
& +\beta_{K+1} x_{i t} I\left(\gamma_{K}<q_{i t} \leq \gamma_{K+1}\right)+\varepsilon_{i t}
\end{aligned}
$$

where subscripts $i$ stands for the cross-sections with $(1 \leq i \leq N)$ and $t$ indexes times $(1 \leq t \leq T) . \mu_{i}$ is the countries-specific fixed effect and the error term $\varepsilon_{i t}$ is independent and identically distributed (iid) with mean zero and finite variance $\sigma_{\varepsilon}^{2} . I($.$) is the indicator function$ indicating the regime defined by the threshold variable $q_{i t}$ the threshold parameter $\gamma . y_{i t}$ is dependent variable and $x_{i t}$ the vector of explanatory variables. $\gamma_{0}=-\infty$, $\gamma_{K+1}=+\infty$. Equation (1) allows for $K$ threshold values and, thus, $(K+1)$ regimes. In each regime, the marginal effect of $x_{i t}\left(\beta_{k}\right)$ on $y_{i t}$ may differ.

Following the modified version of [10] panel threshold model proposed by [14], we consider a discriminator constant which is not individual specific but captures a common effect for all cross-sections. According to these authors, ignoring regime dependent intercepts $\left(\delta_{k}\right)$ can lead to biased estimates of both the thresholds and the corresponding marginal impacts.

$$
\begin{aligned}
y_{i t}= & \mu_{i}+\sum_{k=0}^{K-1}\left(\beta_{k+1}+\delta_{k+1}\right) x_{i t} I\left(\gamma_{k}<q_{i t} \leq \gamma_{k+1}\right) \\
& +\beta_{K+1} x_{i t} I\left(\gamma_{K}<q_{i t} \leq \gamma_{K+1}\right)+\varepsilon_{i t}
\end{aligned}
$$

This formulation assumes that the difference in the regime intercepts, represented by $\left(\delta_{k}\right)$, is not individual specific but the same for all cross-sections. According to [14], omission of any variable correlated with at least one regressor and the dependent variable causes biased estimates, but regime intercepts are a particularly interesting 
case. First, the bias can be clearly interpreted. Second, availability of regime intercepts as regressors is not an issue since they are as easily constructed as the regime-dependent exogenous regressors for a given threshold.

\subsection{Estimation and Test Strategy}

\subsubsection{Estimation Method}

Estimation of the panel threshold model involves several stages. First, estimation of the parameters model requires eliminating the individual effects $\mu_{i}$ by removing individual-specific means and then applying the least squares sequential procedure (see [10] for more details). Indeed, the individual specific effects are eliminated using the standard fixed-effects transformation implying for the identification of $\beta_{k}$ and $\beta_{k+1}$ that the elements of $x_{i t}$ are neither time-invariant nor adding up to a vector of ones. This case applies to regime intercepts which are usually included in each regime in threshold models in pure cross-sectional or time-series contexts. For example, in the case of two regimes, even in the presence of fixed effects it is possible to control for differences in the regime intercepts by including them in all but one regime as in the extension of the following equation ${ }^{2}$ :

$$
y_{i t}=\mu_{i}+\left(\delta_{1}+\beta_{1}\right) x_{i t} I\left(q_{i t} \leq \gamma\right)+\beta_{2} x_{i t} I\left(q_{i t}>\gamma\right)+\varepsilon_{i t}
$$

The seminal contribution of [11] allows us to estimate and make valid statistical inferences on the threshold. There are three statistical issues that need to be addressed in a threshold model: 1) how to jointly estimate the threshold value $\gamma$ and the slope parameters; 2) how to test the hypothesis that a threshold exists and; 3 ) how to construct confidence intervals for $\gamma$ and $\beta$. We briefly discuss each in turn. [11] recommends obtaining the least squares estimate $\hat{\gamma}$ as the value that minimizes the concentrated sum of squared errors, $S_{1}(\gamma)$. The sum of the squared error function depends on $\gamma$ only through the indicator function. Hence, the minimization problem is a step procedure where each step occurs at distinct values of the observed threshold variable $\left(q_{i t}\right)$. After the threshold value $\gamma$ is estimated, it is important to determine whether the threshold effect is statistically significant. In order to test the statistical significance of a threshold effect typically we would want to test the null hypothesis of no threshold effect, $H_{0}: \beta_{1}=\beta_{2}$. However, since $\gamma$ is only identified under the alternative $\left(H_{1}: \beta_{1} \neq \beta_{2}\right)$, the distribution of classical test statistics, such as the Wald and Likelihood ratio tests, are not asymptotically Chi-squared. In essence this is because the likelihood surface is flat with respect to $\gamma$, consequently the information matrix becomes singular and standard

\footnotetext{
${ }^{2}$ There is no reason to limit our analysis to just two regimes. Hence, the estimation approach proposed by [10] and extended by [14] allows a more general specification with $K$ thresholds (i.e. $K+1$ regimes).
}

asymptotic arguments no longer apply. There are methods for handling hypothesis testing within these contexts. In some instances, we are able to bind the asymptotic distribution of likelihood ratio statistics ([15,16]); alternatively their asymptotic distribution must be derived by bootstrap methods (see [11]). The appropriate test statistic is $F_{1}=\frac{S_{0}-S_{1}(\hat{\gamma})}{\hat{\sigma}^{2}}$ where $S_{0}$ and $S_{1}$ are, respecttively, the residual sum of squares under the null hypothesis $H_{0}$ and the alternative $H_{1}$ with $\hat{\sigma}^{2}$ the residual variance under the alternative hypothesis. Once the threshold effect exists, the next question is whether or not the threshold value can be known. The null hypothesis of the threshold value is $H_{0}: \gamma=\gamma_{0}$, and the likelyhood ratio statistics is $L R_{1}(\gamma)=\frac{S_{1}(\gamma)-S_{1}(\hat{\gamma})}{\hat{\sigma}^{2}}$ where $S_{1}(\gamma)$ and $S_{1}(\hat{\gamma})$ are the residual sum of squares from Equation (3) given the true and estimated value, respectively. The null hypothesis is rejected for large value of $L R_{1}$. The asymptotic distribution of $L R_{1}\left(\gamma_{0}\right)$ can be used to form valid asymptotic confidence interval about the estimated threshold values. The statistics of $L R_{1}\left(\gamma_{0}\right)$ are not normally distributed and [11] computed their no-rejection region, $c(\alpha)$ with $\alpha$ the given asymptotic level. He proves that the distribution function has the inverse $c(\alpha)=-2 \ln (1-\sqrt{1-\alpha})$ from which it is easy to compute the critical values. The test rejects the null hypothesis at the asymptotic level $\alpha$ if $L R_{1}\left(\gamma_{0}\right)$ exceeds $c(\alpha)$. The asymptotic $(1-\alpha)$ confidence interval for $\gamma$ is set of values of $\gamma$ such that $L_{1}\left(\gamma_{0}\right) \leq c(\alpha)$.

\subsubsection{Regime Intercepts}

The role of regime intercepts will be discussed in the context of a single threshold model, though it is straightforward to introduce them in a model with multiple thresholds. The elimination of the individual specific effect in Equation (3) with the standard fixed-effects transformation implies for the identification of slope coefficients $\beta_{1}$ and $\beta_{2}$ that the elements of $x_{i t}$ are neither time-invariant nor adding up to a vector of ones. This latter case applies to regime intercepts which are usually included in each regime in threshold models in pure cross-sectional or time-series contexts. Even in the presence of fixed-effects it is possible to control for differences in the regime intercepts by including them in all but one regime as in the following extension of Equation (3):

$$
y_{i t}=\mu_{i}+\beta_{1} x_{i t} I\left(q_{i t} \leq \gamma\right)+\delta_{1} I\left(q_{i t} \leq \gamma\right)+\beta_{2} x_{i t} I\left(q_{i t}>\gamma\right)
$$

This formulation assumes that the difference in the regime intercepts, represented by $\delta_{1}$, is not individual 
specific but the same for all cross-sections. Since Equation (4) has neither been considered by [10] nor any of the numerous studies, e.g. [17,18] or [19], applying his methodology, it seems worthwhile to briefly discuss the role of regime intercepts for the estimation results in the [10] framework.

In case a regime intercept is included, as in specification (4), the slope estimates for each regime are identical to those from a regression using only observations from the respective regime which reflects the orthogonality of the regressors $I\left(x_{i} \leq x_{m}\right)$ and $x_{i} I\left(x_{i}>x_{m}\right)$. Omission of any variable correlated with at least one regressor and the dependent variable causes biased estimates, but regime intercepts are a particularly interesting case. First, the bias can be clearly interpreted. Estimating Equation (3) in the presence of a regime intercept in the data generating process results in a bias proportional to $\hat{\delta}_{1}$ because the orthogonality of the regressors is not preserved anymore. Second, availability of regime intercepts as regressors is not an issue since they are as easily constructed as the regime-dependent exogenous regressors for a given threshold.

Biased estimates of the regression slopes have further consequences in the panel threshold model because the threshold estimates are also obtained by least squares. Only by coincidence, these estimates will be the same for specifications (3) and (4) if a regime intercept is present in the data generating process. Moreover, unbiased estimates of $\beta_{1}$ and $\beta_{2}$ are crucial for the test of the significance of a threshold which is based on the null hypothesis of equality of the two coefficients.

Eventually, the setup in [10] has to be extended to allow for regime intercepts as in Equation (4). First, the null hypothesis to test for the significance of the threshold has to be extended by $\delta_{1}=0$. Second, the derivation of the asymptotic distribution of the threshold estimate now relies on the additional technical assumption that $\delta_{1} \rightarrow 0$ as $N \rightarrow \infty$. It means that the difference in the intercepts between the two regimes is 'small' relative to sample size which is completely analogous to the assumption regarding the slope coefficients. Third, the proof in the appendix in [10] now relies on the following two expressions taking the regime intercept as an additional regressor into account: $\theta^{\prime}=\left(\left(\beta_{2}-\beta_{1}\right)^{\prime}-\delta_{1}\right)$ and
$z_{i t}=\left(x_{i t}^{\prime}\right) C$.

\section{Empirical Analysis}

\subsection{The Variables}

The set of explanatory variables that constitute the vector $x_{i t}$ include; foreign aid as a percentage of GDP, policy index, the institutional quality index, investment as a percentage of GDP and human capital as a measured of secondary enrollment schools and initial income.
The policy variables are openness, inflation and fiscal policy. Openness, a measure of international trade, is believed to affect growth through several channels, such as access to technology from abroad, greater access to a variety of inputs for production and access to broader markets that raise the efficiency of domestic production through increased specialization. There are various measures of openness but in this paper, we use ratio of total trade to GDP. As suggested by [1], budget surplus as a percentage of GDP is included as a measure of fiscal policy. The budget surplus is believed to be an indicator of the stabilizing role of government. In line with [20] inflation is taken as a measure of monetary policy.

$$
\text { Policy }_{i t}=w_{0}+w_{1} \text { fispolicy }_{i t}+w_{2} \text { opens }_{i t}-w_{3} \inf _{i t}+\varepsilon_{i t}
$$

where $w_{0}$ the constant term is the country's predicted growth rate for given values of budget surplus (fishpolicy), trade openness (opens) and the inflation rate (inf) assuming that it had the mean values of all other characteristics. The weights $w_{1}, w_{2}$ and $w_{3}$ are obtained from OLS regression of these variables on growth. The intuition is that the policy index should weight the policies according to their impact on growth.

The policy index is a measure of the quality of economic policy; the higher the index the higher the quality of economic policy. Obviously, countries with good economic policies tend to grow faster than countries with bad economic policy.

The institutional quality index (ircg) is not a weighted average of the institutional variables ${ }^{3}$, but is obtained from OLS regression of corruption, ethnic tension, socioeconomic conditions, law and order, profile investment and government stability.

$$
\begin{aligned}
\text { icrg }_{i t}= & k_{0}+k_{1} \operatorname{corr}_{i t}+k_{2} \text { ethnics }_{i t}+k_{3} \text { socioec }_{i t}+k_{4} \text { law }_{i t} \\
& +k_{5} \operatorname{proinv}_{i t}+k_{6} \text { govstab }_{i t}+v_{i t}
\end{aligned}
$$

The institutional settings within which economic policies are formulated are of crucial importance, because the quality of these institutions can be a primary source of the differences in economic growth among nations. Countries with good institutions such as lower level of confiscation of private properties, lower level of governmental corruption, lower ethnic tensions, and efficient profile investment are expected to grow faster than countries with bad institutions. Poor institutions interfere with economic growth by inducing economic agents to engage in redistributive politics rather economic activity with lower economic returns. The coefficient of institutional quality is expected to be positive.

Another control variable included in equation is investment and human capital. The level of investment is also included as a control variable. The investment/GDP ratio (invest) is used as a proxy for the growth rate of

${ }^{3}$ See Ali et al. (2009) for more details. 
the capital stock. Since the investment/GDP ratio is not reported for the majority of the ECOWAS countries, gross fixed capital formation as a share of GDP is used to represent investment/GDP ratio. The higher the investment is, the higher the growth rate is. Therefore, we expect a positive sign for the coefficient of investment. Human capital (human) is Secondary School Enrollment Rate measures the percentage of school age population that was enrolled in secondary schools. Thus, the GDP growth rate is a positive function of education. We expect a positive sign for the coefficient of this variable.

The key independent variable and the variable of interest is (aid) which is foreign aid expressed as percentage of GDP. The aid variable used is the Effective Development Assistance (EDA), which measures official aid flows as the sum of grants and the grant equivalent of official loans. The grant equivalent of a financial inflow is the amount that, at the time of its commitment, is not expected to be repaid, i.e., the amount subsidized through below-market terms at the time of commitment.

The initial income level (initial) measured as GDP per capita is included to verify the convergence hypothesis. The convergence hypothesis and the steady-state theory predicted in the neoclassical growth theory rests on the premise that countries are similar except for their starting GDP level. Therefore, poor countries are predicted to grow faster than rich countries. If this is true, we expect a negative sign for the coefficient of this variable.

\subsection{Data and Preliminary Analysis}

In this paper, we consider annual data from the ECOWAS countries which are collected from various sources and covered the period 1984 to 2010. Data are collected from the Penn World Table 6.1 and 6.2, World Development Indicators (WDI), the IMF's International
Financial Statistics and the International Country Risk Guide (ICRG).

We are able to identify the regime of the economy with respect to the macroeconomic policy environment and institutional quality which depend on the estimate of the policy index and institutional quality thresholds. Thus we can also investigate all combinations of those regimes. So we can distinguish between four different states as shown in Figure 2.

Figure 2 displays the four states the donors can face when deciding about the aid in recipient countries.

We have to use the threshold estimated $\gamma_{\text {policy }}$ and $\gamma_{\text {institutions }}$ to determine the regime. We are able to distinguish with this approach between a situation where the macroeconomic policy environment and institutional quality are below $\gamma_{\text {policy }} / \gamma_{\text {institutions }}$ (State I), the macroeconomic policy environment is below and institutional quality above $\gamma_{\text {policy }} / \gamma_{\text {institutions }}$ and vice versa (States II and III), and a situation where both are above $\gamma_{\text {policy }} / \gamma_{\text {institutions }}$ (State IV). We can therefore estimate for each case the aid impact on economic growth and compare those to each other.

However, some differences are of special economic growth. Since when comparing States I and II it becomes obvious that only the sign of the institutional quality has changed while the macroeconomic policy environment remains negative (below the threshold value $\gamma_{\text {policy }}$ ) in both cases. The same holds for the States III and IV where again only the macroeconomic policy environment remains positive (above the threshold value $\gamma_{\text {policy }}$ ). The same argumentation applies when comparing States I and III with respect the negative sign of institutional quality (below the threshold value $\gamma_{\text {institutions }}$ ) or positive (above the threshold value $\gamma_{\text {institutions }}$ ). According to our analysis, we expect that the aid negatively affects growth in States I and III and has positive impact in States II and IV.

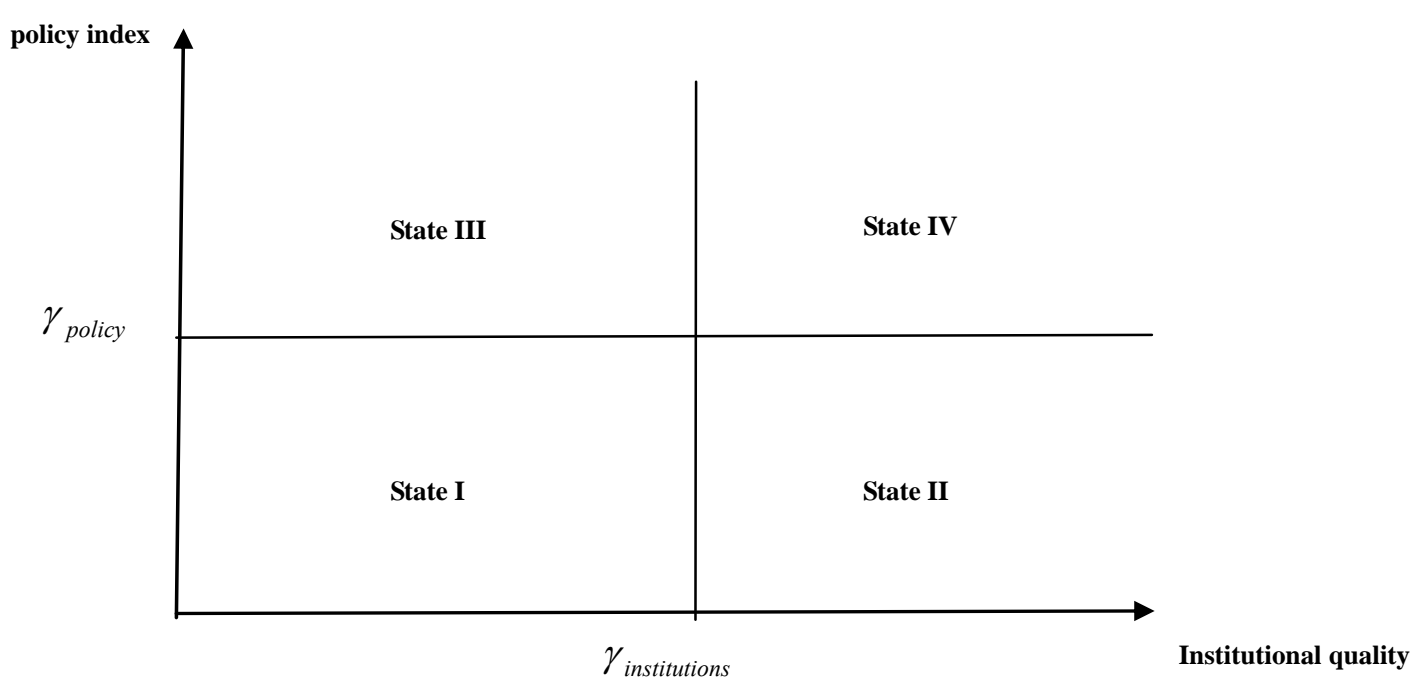

Figure 2. The four states of the economy. 
Having constructed the data we can now separate them into the four states by simply introducing the threshold measures explained in Figure 2.

The summary statistics of the different states together with those for each threshold and linear relationship between aid and growth are given in Table 1. Several interesting insights can be drawn from Table 1. First, following [10], each regime contains at least $5 \%$ of all observations. So we have enough data points for each regime in order to get consistent estimates. Furthermore, for their combination given by the four states the same conclusion can be drawn. Second, the descriptive statistics show that the aid is lower if the policy environment and institutional quality are above their threshold values. This suggests that a stable macroeconomic policy environment and better institutional quality allow a little aid to improve economic grow. However, the aid is higher when the policy environment and institutional quality are below their threshold values. This implies that even they have more quantitative aid; its impact on growth is unclear. Following, the four states, our statistics show that economic is highly efficient if the institutional quality achieves optimal value.

Before conducting the regression investigation as proposed in the recent panel data econometric literature, we tested for possible unit roots in the panels. [10] panel

Table 1. Descriptive statistics.

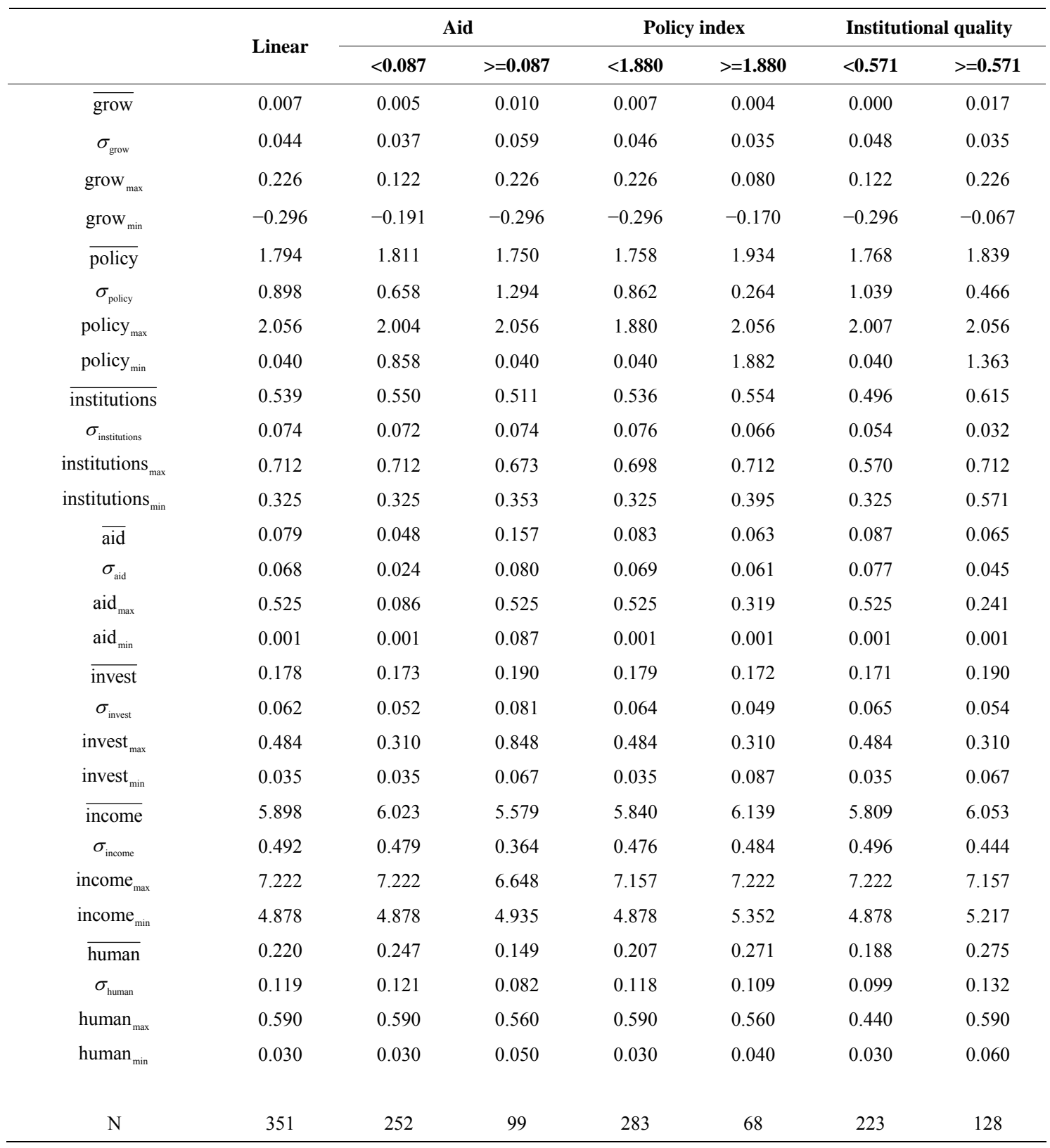


Continued

\begin{tabular}{|c|c|c|c|c|}
\hline & State 1 & State II & State III & State IV \\
\hline$\overline{\text { grow }}$ & -0.003 & 0.021 & 0.004 & 0.004 \\
\hline$\sigma_{\text {grow }}$ & 0.049 & 0.037 & 0.043 & 0.019 \\
\hline grow $_{\max }$ & 0.122 & 0.226 & 0.080 & 0.038 \\
\hline grow $_{\min }$ & -0.296 & -0.067 & -0.170 & -0.036 \\
\hline$\overline{\text { policy }}$ & 1.726 & 1.813 & 1.940 & 1.924 \\
\hline$\sigma_{\text {policy }}$ & 0.990 & 0.377 & 0.234 & 0.293 \\
\hline policy $_{\max }$ & 1.876 & 1.880 & 2.007 & 2.056 \\
\hline policy $_{\min }$ & 0.040 & 1.363 & 1.882 & 1.885 \\
\hline$\overline{\text { institutions }}$ & 0.493 & 0.614 & 0.508 & 0.620 \\
\hline$\sigma_{\text {institutions }}$ & 0.057 & 0.030 & 0.035 & 0.038 \\
\hline institutions $_{\max }$ & 0.570 & 0.698 & 0.571 & 0.712 \\
\hline institutions $_{\min }$ & 0.325 & 0.571 & 0.395 & 0.579 \\
\hline$\overline{\text { aid }}$ & 0.091 & 0.068 & 0.068 & 0.054 \\
\hline$\sigma_{\text {aid }}$ & 0.078 & 0.045 & 0.070 & 0.046 \\
\hline $\operatorname{aid}_{\text {max }}$ & 0.525 & 0.241 & 0.319 & 0.179 \\
\hline $\operatorname{aid}_{\text {min }}$ & 0.001 & 0.001 & 0.001 & 0.015 \\
\hline$\overline{\text { invest. }}$ & 0.171 & 0.193 & 0.168 & 0.179 \\
\hline$\sigma_{\text {invest. }}$ & 0.069 & 0.053 & 0.046 & 0.053 \\
\hline invest. $_{\text {max }}$ & 0.848 & 0.309 & 0.282 & 0.310 \\
\hline invest $_{\text {min }}$ & 0.035 & 0.067 & 0.087 & 0.096 \\
\hline$\overline{\text { income }}$ & 5.731 & 6.041 & 6.168 & 6.097 \\
\hline$\sigma_{\text {income }}$ & 0.443 & 0.472 & 0.572 & 0.326 \\
\hline income $_{\max }$ & 7.109 & 7.157 & 7.222 & 6.734 \\
\hline income $_{\text {min }}$ & 4.878 & 5.217 & 5.352 & 5.601 \\
\hline$\overline{\text { human }}$ & 0.179 & 0.259 & 0.230 & 0.330 \\
\hline$\sigma_{\text {human }}$ & 0.102 & 0.130 & 0.071 & 0.127 \\
\hline human $_{\text {max }}$ & 0.440 & 0.590 & 0.390 & 0.560 \\
\hline human $_{\min }$ & 0.030 & 0.060 & 0.040 & 0.180 \\
\hline $\mathrm{N}$ & 183 & 100 & 40 & 28 \\
\hline
\end{tabular}

Notes: $\bar{x}$ stands for the mean of the respective variable, $x_{\max }$ and $x_{\min }$ for the maximum and minimum realization, while $\sigma_{x}$ is the standard deviation, $N=$ number of observations.

threshold regression model is an extension of the traditional least squared estimation method, in fact. It requires that variables considered in the model need to be stationary in order to avoid the so-called spurious regression ${ }^{4}$. Since the stationarity properties of the variables are studied, i.e. the examination of whether or not the variables appear to contain panel unit roots. Non-stationary panels have become extremely popular and have attracted much attention in both theoretical and empirical research over

${ }^{4}$ Spurious regression is argued in Granger and Newbold (1974) that the estimation of the relationship among non-stationary series is easily getting higher $\mathrm{R}^{2}$ and $\mathrm{t}$ statistics. the last decade. A number of panel unit root tests have been proposed in the literature, in this research, we use [21-24] all based on a null hypothesis that a unit root exists in the panels. Indeed, the [21,22] panel unit root tests assume a homogeneous autoregressive unit root under the alternative hypothesis whereas [23] allows for a heterogeneous autoregressive unit root under the alternative hypothesis. Fundamentally, the [23] test averages the individual augmented Dickey-Fuller (ADF) test statistics. Both the $[21,23]$ tests suffer from a dramatic loss of power when individual specific trends are included, which is due to the bias correction. However, the [22] 
panel unit root test does not rely on bias correction factors. Monte Carlo experiments showed that the [22] test yields substantially higher power and smallest size distortions compared to [21,23]. [24,25] suggest comparable unit root tests to be performed using the non-parametric Fisher statistic.

Table 2 displays the results of panel unit root tests in levels for all the variables. All tests reject the null hypothesis of a unit root in the examined series. As regards to institutional quality and investment, the tests failed to reject the null hypothesis of unit root. According to [26], this result may be due to the fact that the tests have a low power against nonlinear stationary process. From the nonlinear unit root test, we can conclude that all the variables in the paper are stationarity. It was deemed safe to continue with the panel data estimates of the above econometric specification.

Suspecting strong collinearity between some regressors, Table 3 reports the pairwise correlation coefficients between all the candidate variables of the models. As can be seen, our results suggest that the inclusion of all these variables in the same model pose none problem of multicollinearity. Indeed, coefficients of correlation appear quite low on the whole.

Table 2. Panel unit root test results.

\begin{tabular}{ccccccc}
\hline & Aid & Policy & Institutions & Investment & Initial income & Human capital \\
\hline Intercept & & & & & & \\
Levin, Lin and Chin & $-2.928^{\mathrm{a}}$ & $-2.242^{\mathrm{b}}$ & -1.244 & 1.714 & $-4.851^{\mathrm{a}}$ & $-2.247^{\mathrm{b}}$ \\
& $(0.002)$ & $(0.013)$ & $(0.101)$ & $(0.957)$ & $(0.000)$ & $(0.012)$ \\
Breitung & $-2.543^{\mathrm{a}}$ & $-1.761^{\mathrm{b}}$ & 0.559 & -0.379 & $-3.711^{\mathrm{a}}$ & $-3.913^{\mathrm{a}}$ \\
& $(0.006)$ & $(0.039)$ & $(0.712)$ & $(0.352)$ & $(0.000)$ & $(0.000)$ \\
Im, Pesaran and Shin & $-2.779^{\mathrm{a}}$ & $-1.745^{\mathrm{b}}$ & -0.497 & 0.668 & $-4.251^{\mathrm{a}}$ & $-2.554^{\mathrm{a}}$ \\
Fisher-ADF & $(0.003)$ & $(0.041)$ & $(0.310)$ & $(0.748)$ & $(0.000)$ & $(0.005)$ \\
& $49.383^{\mathrm{a}}$ & $41.953^{\mathrm{b}}$ & 30.353 & 24.192 & $68.092^{\mathrm{a}}$ & $69.023^{\mathrm{a}}$ \\
Fisher-PP & $(0.004)$ & $(0.025)$ & $(0.253)$ & $(0.565)$ & $(0.000)$ & $(0.000)$ \\
Intercept + trend & $72.120^{\mathrm{a}}$ & $76.062^{\mathrm{a}}$ & $35.575^{\mathrm{c}}$ & $37.930^{\mathrm{c}}$ & $174.617^{\mathrm{a}}$ & $148.824^{\mathrm{a}}$ \\
Levin, Lin and Chin & $(0.000)$ & $(0.000)$ & $(0.090)$ & $(0.062)$ & $(0.000)$ & $(0.000)$ \\
& & & & & $-8.500^{\mathrm{a}}$ & $-5.813^{\mathrm{a}}$ \\
Breitung & $-3.499^{\mathrm{a}}$ & $-3.265^{\mathrm{a}}$ & 1.282 & 1.278 & $(0.000)$ & $(0.000)$ \\
& $(0.000)$ & $(0.000)$ & $(0.900)$ & $(0.899)$ & $-4.259^{\mathrm{a}}$ \\
Fisher-PP & $-2.562^{\mathrm{a}}$ & -0.450 & $-2.185^{\mathrm{b}}$ & 3.096 & $-7.400^{\mathrm{a}}$ & $(0.000)$ \\
Fisher-ADF & $(0.005)$ & $(0.326)$ & $(0.014)$ & $(0.999)$ & $(0.000)$ & $-6.011^{\mathrm{a}}$
\end{tabular}

Notes: Figures in square brackets are probability values. a, b, and c represent significance at $1 \%, 5 \%$, and $10 \%$ respectively. The maximum number of lags is set to be four. MAIC is used to select the lag length. The bandwidth is selected using the Newey-West method. Barlett is used as the spectral estimation method.

Table 3. Correlation matrix of the variables include in the model.

\begin{tabular}{|c|c|c|c|c|c|c|c|}
\hline & Aid & Growth & Policy & Institutions & Investment & Initial income & Human capital \\
\hline Aid & 1.000 & & & & & & \\
\hline Growth & 0.055 & 1.000 & & & & & \\
\hline Policy & -0.311 & 0.018 & 1.000 & & & & \\
\hline Institutions & -0.224 & 0.170 & 0.381 & 1.000 & & & \\
\hline Investment & 0.321 & 0.188 & 0.018 & 0.249 & 1.000 & & \\
\hline Initial income & -0.419 & 0.066 & 0.387 & 0.360 & 0.058 & 1.000 & \\
\hline Human capital & -0.369 & 0.112 & 0.174 & 0.300 & 0.201 & 0.429 & 1.000 \\
\hline
\end{tabular}


In fact, several reasons might explain the low correlation between aid and economic growth outcomes. One of them is the phenomenon of aid fungibility, i.e. aid could be redirected by the recipient country toward sectors other than those originally provided in the commitments.

In order to test the presence of non-linear effect with respect to aid, institutional quality and the policy index we apply the Hansen's test described above, with 1000 bootstrap replication to compute the p-value of the F-test statistic.

The estimated threshold and the p-value of the F-test for the null of no threshold are reported in Table 4. The results show that the linearity hypothesis is strongly rejected in favour of threshold regression for both three variables. This confirms the presence of nonlinearities in aid-growth relationship. Once the presence of threshold effect is confirmed the next step is to estimate the threshold regression following the procedure as discussed in the methodology section.

\subsection{Aid Thresholds and Economic Performance}

Let us now apply the modified panel threshold model to the analysis of the impact of aid on economic growth in ECOWAS countries. To that aim, consider the following threshold model of the aid-growth relationship:

$$
\begin{aligned}
\operatorname{grow}_{i t}= & \mu_{i}+\beta_{1} \operatorname{Aid}_{i t} I\left(\operatorname{Aid}_{i t}<\gamma\right)+\delta_{1} I\left(\operatorname{Aid}_{i t}<\gamma\right) \\
& +\beta_{2} \operatorname{Aid}_{i t} I\left(\operatorname{Aid}_{i t} \geq \gamma\right)+\theta_{1} \text { invest }_{i t}+\theta_{2} \text { initial }_{i t} \\
& +\theta_{3} \operatorname{human}_{i t}+\theta_{4} \text { policy }_{i t}+\theta_{5} \operatorname{ircg}_{i t}+\varepsilon_{i t}
\end{aligned}
$$

where $I\left(\operatorname{Aid}_{i t}<\gamma\right)$ and $I\left(\operatorname{Aid}_{i t} \geq \gamma\right)$ are indicator functions which take the value of one if the term between parentheses is true, and are zero otherwise. This model specifies the effects of Aid with two coefficients: of $\beta_{1}$ and $\beta_{2} . \beta_{1}$ denotes the effect of Aid below the threshold level $\gamma$, and $\beta_{2}$ denotes the effect of Aid exceeding the threshold level $\gamma$.

Table 5 presents the estimation results obtained of Equation (7) and includes two parts. The first part of the table displays the regime-dependent coefficients of aid on growth. Specifically, $\hat{\beta}_{1}\left(\hat{\beta}_{2}\right)$ denotes the marginal effect of aid on growth in the low (high) aid regime, i.e. when aid is below (above) the estimated threshold value. The coefficients of the control variables are presented in the second part of the table. Our results reveal that the coefficients of aid have different signs and significances across the low and high aid regimes. When aid is above the threshold value $(\hat{\gamma} \geq 0.087)$, our results indicate that foreign aid have positive but insignificant impact on economic growth. However, when aid is below the threshold value, there are negative relationship between aid and growth and aid marginal effect is significant. This negative impact can be explained by the simple fact that a permanent rise in aid reduces long term capital accumulation and labour supply and by extension reduces the rate of economic growth [27]. These findings suggest that foreign aid perpetuates poor economic policies and postpone reform; limited absorptive capacity in the recipient country reduces the effectiveness of aid and aid reduces both domestic private and public saving (see $[28,29])$. Moreover, our results have shown how development assistance leads to distortion and disruption in the domestic economy.

Regarding the control variables, we notice that investment and institutional quality and human capital have positive impact on growth, while the initial income is negatively and significantly correlated with economic growth. This result confirms the conditional convergence hypothesis of [30-32].

Table 4. F-test of null of no threshold $\left(H_{0}: \beta_{1}=\beta_{2}\right)$.

\begin{tabular}{cccc}
\hline & Aid & Policy index & $\begin{array}{c}\text { Institutional } \\
\text { quality }\end{array}$ \\
\hline Estimated threshold & 0.087 & 1.880 & 0.571 \\
Confidence Interval & {$[0.0040 .210]$} & {$[1.4321 .952]$} & {$[0.5450 .632]$} \\
LM-test & 25.435 & 17.952 & 37.930 \\
p-value & 0.015 & 0.037 & 0.008 \\
critical values & & & \\
$\mathbf{1 0 \%}$ & 16.370 & 13.946 & 20.790 \\
$\mathbf{5 \%}$ & 20.617 & 16.747 & 24.724 \\
$\mathbf{1 \%}$ & 26.674 & 21.648 & 34.230 \\
\hline
\end{tabular}

Table 5. Aid-growth threshold regressions using Aid as a threshold.

\begin{tabular}{cccccccc}
\hline \multicolumn{2}{l}{ Regime-dependent coefficients } & \multicolumn{5}{c}{ Regime-independent coefficients } \\
\hline$\beta_{1}$ & $\beta_{2}$ & $\begin{array}{c}\text { initial } \\
\text { income }\end{array}$ & invest. & $\begin{array}{c}\text { Human } \\
\text { capital }\end{array}$ & $\begin{array}{c}\text { Policy } \\
\text { index }\end{array}$ & $\begin{array}{c}\text { Institutional } \\
\text { quality }\end{array}$ & $\hat{\delta}_{1}$ \\
\hline$-0.186^{\mathrm{a}}$ & 0.017 & $-0.010^{\mathrm{a}}$ & $0.097^{\mathrm{a}}$ & $0.014^{\mathrm{c}}$ & -0.002 & $0.099^{\mathrm{a}}$ & $0.014^{\mathrm{b}}$ \\
$(0.059)$ & $(0.039)$ & $(0.002)$ & $(0.025)$ & $(0.008)$ & $(0.002)$ & $(0.015)$ & $(0.007)$ \\
$\mathrm{R} 2=0.344$ & & & & & & & \\
F-stat $=24.748$ & & & & & & & \\
p-value $=0.000$ & & & & & & & \\
\hline
\end{tabular}

Notes: Standard errors are given in parentheses. a, b and c indicate significance at the $1 \%, 5 \%$ and $10 \%$ level. 


\subsection{Aid Impact Conditional to Policy Environment}

Following [33] argument that aid positively influences long term growth in countries with good policy environment, we use panel threshold model to investigate impact of aid conditional to stable macroeconomic policy environment. With regard to aid, variable that holds the interest of this research, it is expected that the relationship is positive growth in normal regime, i.e., when policy index is greater or equal to an endogenous threshold value (good policy environment). We assume that the aid impact on economic growth depends on a level of policy index. Thus our nonlinear model specification is as follows:

$$
\begin{aligned}
\operatorname{grow}_{i t}= & \mu_{i}+\beta_{1} \operatorname{Aid}_{i t} I\left(\text { Policy }_{i t}<\gamma\right)+\delta_{1} I\left(\text { Policy }_{i t}<\gamma\right) \\
& +\beta_{2} \operatorname{Aid}_{i t} I\left(\text { Policy }_{i t} \geq \gamma\right)+\theta_{1} \text { invest }_{i t}+\theta_{2} \text { initial }_{i t} \\
& +\theta_{3} \operatorname{human}_{i t}+\theta_{4} \operatorname{ircg}_{i t}+\varepsilon_{i t}
\end{aligned}
$$

where $I\left(\right.$ Policy $\left._{i t}<\gamma\right)$ and $I\left(\right.$ Policy $\left._{i t} \geq \gamma\right)$ are indicator functions which take the value of one if the term between parentheses is true, and are zero otherwise. This model specifies the effects of Aid with two coefficients: of $\beta_{1}$ and $\beta_{2} . \beta_{1}$ denotes the effect of Aid below the threshold level $\gamma$, and $\beta_{2}$ denotes the effect of Aid exceeding the threshold level $\gamma$.

To examine the affect of aid on growth in the presence of good policy environment, we estimate the Equation 8 the results are reported in Table 6. Our investigation shows that, on unstable macroeconomic policy environment (low policy regime) foreign aid has a positive effect on the economic growth rate; however, this positive relationship is not statistically significant. This result is consistent with [7,8,34-36] analysis which states that macroeconomic environment has no significant influence on the link between aid and economic growth. On the other side, in high policy regime, the marginal impact of aid on economic performance is positive and statistically significant. These findings indicate that foreign aid does have some positive impact on economic performance, conditional on stable macroeconomic policy environment (when policy index is above 1.880). The result is similar to that found by [33]. It shows that the effectiveness of aid in the growth process depends on the level and quality of economic policies. In addition, when country size is included the growth model, the impact of aid is positive, larger and significant (see $[33,1,37])$. These results imply aid effectiveness depends upon macroeconomic policies. There are two possible justifications for the positive effect of aid on growth in the presence of good policy. Stable macroeconomic indicators are more attractive for the investor. High inflation and high budget deficit may cause the macroeconomic instability which discourages the investment. High non developing expenditures cause the high budget deficit. In case of high budget deficit, foreign aid may be used for government consumption instead of investment purpose. All of the control variables (the regime independent regressors) have expected sign and are statistically significant.

Our finding suggests that sound economic management policy in terms of low inflation, trade openness and low budget deficit is crucial for aid effectiveness. There is need to implement appropriate policy measure, in order to achieve the positive impact of foreign aid on economic growth through minimizing budgetary deficits, lower the inflation rate and to achieve trade openness.

\subsection{Aid Impact Conditional to Institutional Quality}

Let us now use the panel threshold model specification to the investigation of the effect of aid on economic growth conditional to institutional quality in ECOWAS countries. To that aim, consider the following threshold model of the Aid-growth nexus:

$$
\begin{aligned}
\operatorname{grow}_{i t}= & \mu_{i}+\beta_{1} \operatorname{Aid}_{i t} I\left(\operatorname{ircg}_{i t}<\tau\right)+\delta_{1} I\left(\operatorname{ircg}_{i t}<\tau\right) \\
& +\beta_{2} \operatorname{Aid}_{i t} I\left(\operatorname{ircg}_{i t} \geq \tau\right)+\theta_{1} \text { invest }_{i t} \\
& +\theta_{2} \text { initial }_{i t}+\theta_{3} \text { human }_{i t}+\theta_{4} \text { Policy }_{i t}+\varepsilon_{i t}
\end{aligned}
$$

where $I\left(\operatorname{ircg}_{i t}<\tau\right)$ and $I\left(\operatorname{ircg}_{i t} \geq \tau\right)$ are indicator functions which take the value of one if the term between parentheses is true, and are zero otherwise.

Table 6. Aid-growth threshold regressions using a conditional variable (policy index) as a threshold.

\begin{tabular}{ccccccc}
\hline \multicolumn{2}{c}{ Regime-dependent coefficients } & \multicolumn{5}{c}{ Regime-independent coefficients } \\
\hline$\beta_{1}$ & $\beta_{2}$ & $\begin{array}{c}\text { Initial } \\
\text { income }\end{array}$ & invest. & $\begin{array}{c}\text { Human } \\
\text { capital }\end{array}$ & $\begin{array}{c}\text { Institutional } \\
\text { quality }\end{array}$ & $\hat{\delta}_{1}$ \\
\hline 0.027 & $0.125^{\mathrm{a}}$ & $-0.006^{\mathrm{b}}$ & $0.073^{\mathrm{a}}$ & $0.025^{\mathrm{a}}$ & $0.103^{\mathrm{a}}$ & $-0.007^{\mathrm{c}}$ \\
$(0.036)$ & $(0.037)$ & $(0.003)$ & $(0.026)$ & $(0.009)$ & $(0.016)$ & $(0.004)$ \\
$\mathrm{R} 2=0.362$ & & & & & \\
F-stat $=26.726$ & & & & & \\
p-value $=0.000$ & & & & & \\
\hline
\end{tabular}

Notes: Standard errors are given in parentheses. $\mathrm{a}, \mathrm{b}$ and $\mathrm{c}$ indicate significance at the $1 \%, 5 \%$ and $10 \%$ level. 
Table 7 indicates the results obtained with respect to the institutional quality conditioned in aid-growth nexus. Our findings suggest that for the low-institutional quality regime (in which the institutional quality is below 0.571 ), the marginal impact of aid on economic growth is negative and strongly significant. In the better institutions regime, our results show a positive impact of aid on growth and this impact is statistically significant. Strongly positive and significant coefficient of aid in aidgrowth relationship implies that impact of aid on growth is function of institutional quality. An interesting finding is that the marginal impacts of aid on growth when we take institutional quality as condition variable are more important than to consider macroeconomic policy environment as condition variable. Therefore, controlling low institutional quality regime should be the main goal for policymakers in ECOWAS zone since in this regime more aid is detrimental to economic growth.

From the previous results, it is clear that in the midst of current efforts to achieve the Millennium Development Goals (MDGs) in ECOWAS zone, the need for foreign assistance is inevitable. However, no amount of foreign assistance will promote sustainable growth and development in ECOWAS countries if the problem of unstable macroeconomic environment and bad institutional quality persists. It is, therefore, crucial for governments in the ECOWAS area to improve institutional quality and to pursue economic policies that are conducive to, among others, low inflation, productive budgetary balance and a competitive environment, and that attend to the incessant corruption and political instability.

\subsection{Aid Impact Conditional to Combination of Two Indexes}

From this econometric approach, we identify four states of the economy consistent with the results of the growth framework. Using these four states, we are able to estimate the relation between aid and economic growth in nonlinear fashion in each state based on the deviation from macroeconomic policy environment and the institutional quality. Our model specification is:

$$
\begin{aligned}
\operatorname{grow}_{i t}= & \mu_{i}+\beta_{1} \operatorname{Aid}_{i t} I\left(\text { Policy }_{i t}<\gamma ; \operatorname{ircg}_{i t}<\tau\right)+\delta_{1} I\left(\text { Policy }_{i t}<\gamma ; \operatorname{ircg}_{i t}<\tau\right) \\
& +\beta_{2} \operatorname{Aid}_{i t} I\left(\text { Policy }_{i t}<\gamma ; \operatorname{ircg}_{i t} \geq \tau\right)+\beta_{3} \operatorname{Aid}_{i t} I\left(\text { Policy }_{i t} \geq \gamma ; \operatorname{ircg}_{i t}<\tau\right) \\
& +\beta_{4} I\left(\text { Policy }_{i t} \geq \gamma ; \operatorname{ircg}_{i t} \geq \tau\right)+\theta_{1} \text { invest }_{i t}+\theta_{2} \text { initial }_{i t}+\theta_{3} \operatorname{human}_{i t}+\varepsilon_{i t}
\end{aligned}
$$

where $\left(\right.$ Policy $_{i t}<\gamma ;$ ircg $\left._{i t}<\tau\right)$ indicates state1,

$\left(\right.$ Policy $\left._{i t}<\gamma ; \operatorname{ircg}_{i t} \geq \tau\right)$ state 2,

$\left(\right.$ Policy $\left._{i t} \geq \gamma ; \operatorname{ircg}_{i t}<\tau\right)$ state 3 and

$\left(\right.$ Policy $\left._{i t} \geq \gamma ; \operatorname{ircg}_{i t} \geq \tau\right)$ represents state 4. This model specifies the effects of Aid with four coefficients: of $\beta_{1}$, $\beta_{2}, \beta_{3}$ and $\beta_{4} . \beta_{j}$ denotes the effect of Aid in state $j(j=1,2,3,4)$.

The estimation results of Equation 10 are presented in

Table 8. Using the combination terms which signal the state of the economy, we find that the impact of aid on growth is negative in the States I and III (situation where institutional quality is below its threshold value and macroeconomic policy environment is above or below its threshold value). The marginal impact of aid is statistically insignificant in state I but strongly significant in state III. This negative relationship between aid and economic growth strength the idea that resources transfer from donors to ECOWAS countries are oriented towards their own economic and strategic interest instead of needs of the recipient countries. The negative effect of aid on growth in these countries can be justified on the following arguments. First, aid may be used to invest either in less productive sector or to increase government consumption. This is consistent with finding of [27] that aid leakage (outflow) into non-productive expenditures in the public sector may be the cause of negative relationship between aid and economic growth. In fact, in a recent book, [38,39] argues that not only billions of dollars of aid spent have not significantly improved the well-being of Africans, but rather they have worsened the situation. Second, unstable aid volatile macroeconomic environment and bad institutional quality have spoiled the favorable effect of aid on economic growth. Third, aid into ECOWAS countries is used to substitute government's inability to tax its own citizens because of political pressure from elite groups.

In contrast to States I and III, our results show the positive and statistically significant relationship between aid and growth in States II and IV. However, the marginal effect of aid on growth is more consistent in terms of magnitude in state II $\left(\beta_{2}=0.206\right)$ against $\left(\beta_{4}=0.120\right)$ in state IV. Our results suggest that foreign aid accelerates economic growth by supplementing domestic capital formation.

Researcher highlights some key issues which may undermine the impact of foreign aid on economic growth. These include donors conditionality attached to aid inflow, stable macroeconomic environment in aid recipient country, institutional quality, governance issues; donors tide the some portion of aid and donors strategic motives for the allocation of aid. Among these two reasons are highly concerned in the management of aid inflow into ECOWAS countries and its contribution for ECOWAS economy. These reasons are institutional quality in 
Table 7. Aid-growth threshold regressions using a conditional variable (institutional quality) as a threshold.

\begin{tabular}{ccccccc}
\hline \multicolumn{2}{c}{ Regime-dependent coefficients } & \multicolumn{5}{c}{ Regime-independent coefficients } \\
\hline$\beta_{1}$ & $\beta_{2}$ & $\begin{array}{c}\text { initial } \\
\text { income }\end{array}$ & invest. & $\begin{array}{c}\text { Human } \\
\text { capital }\end{array}$ & $\begin{array}{c}\text { Policy } \\
\text { index }\end{array}$ & $\hat{\delta}_{1}$ \\
\hline$-0.096^{\mathrm{a}}$ & $0.201^{\mathrm{a}}$ & $-0.006^{\mathrm{b}}$ & $0.139^{\mathrm{a}}$ & $0.018^{\mathrm{c}}$ & -0.001 & $0.008^{\mathrm{b}}$ \\
$(0.033)$ & $(0.064)$ & $(0.003)$ & $(0.023)$ & $(0.010)$ & $(0.002)$ & $(0.004)$ \\
$\mathrm{R} 2=0.350$ & & & & & & \\
F-stat $=21.701$ & & & & & & \\
p-value $=0.000$ & & & & & & \\
\hline
\end{tabular}

Notes: Standard errors are given in parentheses. $\mathrm{a}, \mathrm{b}$ and $\mathrm{c}$ indicate significance at the $1 \%, 5 \%$ and $10 \%$ level.

Table 8. Estimation results of Aid-growth threshold depending on the state of the economy.

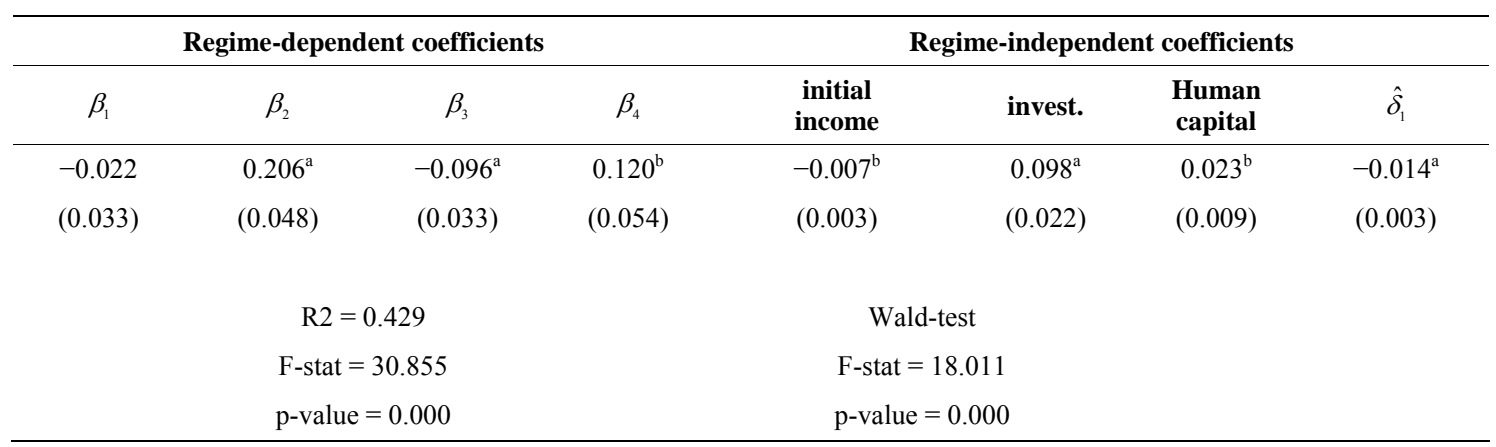

Notes: Standard errors are given in parentheses. $\mathrm{a}, \mathrm{b}$ and $\mathrm{c}$ indicate significance at the $1 \%, 5 \%$ and $10 \%$ level.

ECOWAS zone and macroeconomic policy instability in this area.

The major point emerging from this study is that foreign aid has positive impact on economic growth of ECOWAS countries conditional on sound macroeconomic policies and better institutional quality. Based on the empirical results we find that foreign aid and growth has negative relationship in States I and III while this relation has positive and significant in States II and IV. The interesting results emerge in state II, i.e. if macroeconomic policy environment is below its threshold value and institutional quality is above its threshold value. Our finding suggests that better institutional quality in terms of lower risk of contract repudiation, lower level of governmental corruption, efficient government stability and lower ethnic tensions is crucial for aid effectiveness. Therefore, it is desirable for ECOWAS policymakers to target state II and good institutional quality regime should be the main goal for these countries.

\section{Conclusions}

The belief that foreign aid helps to promote sustainable economic growth and improves the welfare in developing countries is debatable issue since its start. A large body of literature now is available on aid effectiveness but the issue regarding its contribution for growth and welfare remains controversy. The aim of our paper is to investigate whether aid effectiveness depends on the macro- economic policy environment and institutional quality in ECOWAS countries. For this purpose, we have estimated the impact of foreign aid on economic growth by considering the macroeconomic policy environment, institutional quality and the combination of two latter indexes. Therefore, we use [14] the approach based on the panel of 13 ECOWAS countries covering the period from 1984 to 2010. According to our econometric results, the null hypothesis of linearity against the alternative of a nonlinear specification is rejected by the data. Hence, the relationship between aid and growth can be better modeled as a nonlinear model. The paper finds that aid into ECOWAS area will be effectively conditional on a stable macroeconomic policy environment and better institutional quality. In other words, the increasing flows of aid into ECOWAS countries have not promoted meaningful development due to the unstable macroeconomic environment and bad institutional quality. Most countries are characterized by policy inconsistencies, the poor institutional framework, the high level of corruption, incessant political crises and ethnic tension. This will be an important result for the policymakers and international financial institutions, which increasingly favour conditionality and selectivity in the allocation of aid resources. The major policy implication of our results is not a call for a reduction of foreign aid but rather a call for rethinking strategies for international assistance and redesigning existing aid programs. 
From a policy perspective, the present research offers three interesting insights. First, increasing transfer without any conditions may not only be ineffective but may strongly hurt economic performance of ECOWAS countries. According to our investigation, no amount of foreign assistance will promote sustainable growth and development in ECOWAS countries if the problem of unstable macroeconomic environment and bad institutional quality persists. The second insight is that institutional quality is a sine qua non condition for aid to promote economic performance. Hence, States II and IV are identified as determinant regimes for the effective contribution of aid to sustainable growth and improve the welfare in ECOWAS countries. Finally, from the two conditional indexes, institutional quality is more important condition through which aid positively affects economic growth. Making access to better institutional quality may be a way to spur economic growth even in a bad macroeconomic policy environment. It is, therefore, crucial for governments in the ECOWAS area to improve institutional quality and to pursue economic policies that are conducive to, among others, low inflation, productive budgetary balance and a competitive environment, and that attend to the incessant corruption and political instability. Unless such measures are taken, the problem of slow growth will remain unabated. Our results also advocate the development of alternative mechanisms for aid, as aid flows are shown to have an uncertain effect on the growth performance of the recipients. Therefore, it is worth investigating how the two instruments, foreign aid and institutional quality, work together.

\section{REFERENCES}

[1] C. Burnside and D. Dollar, "Aid, Policies, and Growth: Revisiting the Evidence," Policy Research Working Paper No. 3251, The World Bank, Washington DC, 2004. http://dx.doi.org/10.1596/1813-9450-3251

[2] P. Mosley, J. Hudson and S. Horrell, "Aid, the Public Sector and the Market in Less Developed Countries," Economic Journal, Vol. 97, No. 387, 1987, pp. 616-641. http://dx.doi.org/10.2307/2232927

[3] P. Boone, "Politics and the Effectiveness of Foreign Aid," European Economic Review, Vol. 40, No. 2, 1996, pp. 289-329.

http://dx.doi.org/10.1016/0014-2921(95)00127-1

[4] H. Hansen and F. Tarp, "Aid and Growth Regressions," Journal of Development Economics, Vol. 64, No. 2, 2001, pp. 547-570. http://dx.doi.org/10.1016/S0304-3878(00)00150-4

[5] G. F. Papanek, "The Effect of Aid and Other Resource Transfers on Savings and Growth in Less Developed Countries," Economic Journal, Vol. 82, No. 327, 1972, pp. 934-950. http://dx.doi.org/10.2307/2230259

[6] M. Islam, "Regime Changes, Economic Policies and the Effect of Aid on Growth," Journal of Development Stud- ies, Vol. 41, No. 8, 2005, pp. 1467-1492. http://dx.doi.org/10.1080/00220380500187828

[7] C. Dalgaard, H. Hansen and F. Tarp, "On the Empirics of Foreign Aid a01Vol. 32, No. 3, 1993, pp. 485-511. http://dx.doi.org/10.1016/0304-3932(93)90027-D

[8] A. Levin, C. F. Lin and C. Chu, "Unit Root Tests in Panel Data: Asymptotic and Finite-Sample Properties," Journal of Econometrics, Vol. 108, No. 1, 2002, pp. 1-24. http://dx.doi.org/10.1016/S0304-4076(01)00098-7

[9] J. Breitung, "The Local Power of Some Unit Root Tests for Panel Data," Advances in Econometrics, Vol. 15, 2001, pp. 161-177. http://dx.doi.org/10.1016/S0731-9053(00)15006-6

[10] K. S. Im, M. H. Pesaran and Y. Shin, "Testing for Unit Roots in Heterogeneous Panels," Journal of Econometrics, Vol. 115, No. 1, 2003. pp. 53-74. http://dx.doi.org/10.1016/S0304-4076(03)00092-7

[11] G. S. Maddala and S. Wu, "A Comparative Study of Unit Root Tests with Panel Data and a New Simple Test," Oxford Bulletin of Economics and Statistics, Special Issue, 1999, pp. 631-652. http://dx.doi.org/10.1111/1468-0084.61.s1.13

[12] I. Choi, "Unit Root Tests for Panel Data," Journal of International Money and Finance, Vol. 20, No. 2, 2001, pp. 249-272. http://dx.doi.org/10.1016/S0261-5606(00)00048-6

[13] T. Omay and E. O. Kan, "Re-Examining the Threshold Effects in the Inflation-Growth Nexus with Cross-Sectionally Dependent Non-Linear Panel: Evidence from Six Industrialized Economies," Economic Modelling, Vol. 27, No. 5, 2010, pp. 998-1005. http://dx.doi.org/10.1016/j.econmod.2010.04.011

[14] L. Gong and H.-F. Zou, "Foreign Aid Reduces Labour Supply and Capital Accumulation," Review of Development Economics, Vol. 5, No. 1, 2001, pp. 105-118. http://dx.doi.org/10.1111/1467-9361.00110

[15] P. Boone, "The Impact of Foreign Aid on Savings and Growth," Centre for Economic Performance, Working Paper No. 677, 1994.

[16] R. Rajan and A. Subramanian, "Aid and Growth, What Does the Cross Country Evidence Really Show?" IMF Working Paper No. 05/127, 2005.

[17] R. J. Barro, "Economic Growth in A Cross-Section of Countries," Quarterly Journal of Economics, Vol. 106, No. 2, 1991, pp. 407-443. http://dx.doi.org/10.2307/2937943

[18] R. J. Barro and X. Sala-i-Martin, "Economic Growth," 2nd Edition, MIT Press, Cambridge, 2004.

[19] R. J. Barro and X. Sala-i-Martin, “Convergence," Journal of Political Economy, Vol. 100, No. 2, 1992, pp. 223-251. http://dx.doi.org/10.1086/261816

[20] C. Burnside and D. Dollar, "Aid, Policies and Growth," American Economic Review, Vol. 90, No. 4, 2000, pp. 847868. http://dx.doi.org/10.1257/aer.90.4.847

[21] W. Easterly, R. Levine and D. Roodman, "Aid, Policies, and Growth: Comment," American Economic Review, Vol. 94, No. 3, 2004, pp. 774-780. 
http://dx.doi.org/10.1257/0002828041464560

[22] W. Easterly, R. Levine and D. Roodman, "New Data, New Doubts: A Comment on Burnside and Dollar's 'Aid, Policies, and Growth' (2000)," American Economic Review, Vol. 94, No. 3, 2003, pp. 774-780.

[23] R. G. Murphy and N. G. Tresp, "Government Policy and the Effectiveness of Foreign Aid," Department of Economics, Boston College, Chestnut Hill, 2006.

[24] E. Alvi, D. Mukherjee and E. K. Shukralla, "Foreign Aid, Growth, Policy and Reform," Economics Bulletin, Vol.
15, No. 6, 2006, pp. 1-9.

[25] D. Moyo, "Dead Aid: Why Aid Is Not Working and How There Is a Better Way for Africa," Farrar, Straus and Giroux, New York, 2009.

[26] Y. M. Batana, "Aid and Poverty in Africa: Do Well-Being Measures Understate the Progress?" African Development Review, Vol. 22, No. 3, 2010, pp. 452-469. http://dx.doi.org/10.1111/j.1467-8268.2010.00256.x 